\title{
Minimized Disaster Risk on Multifunction Building through Behavior Analysis Prediction, Density and Usage Movement Inside The Building
}

\author{
MahendraWardhana ${ }^{1}$ \\ Interior Design Department FTSP-ITS ${ }^{1}$ \\ *Corresponding author: mahendra@interior.its.ac.id
}

\begin{abstract}
The number of disasters that struck the building is influenced by various factors. Important factors are often the cause is such as natural disasters, high accelerated and suddenly activity, the magnitude of the circulation that supports, as well as the availability of other supporting facilities in the building. The density of the building is the focus of major concern in minimizing the number of victims in the building when the disaster occurred. Increasing accidents victims may occur due to tightness when the evacuation or in an attempt to escape. Efforts to minimize such casualties into account the circumstances of users of the building. One alternative in predicting users building density and the flow of circulation are the ESVA (Environmental Socialization Value Analysis) analysis method. This method calculated the number of users and resources to support the building. Mark or grade obtained will illustrate the high risk of accidents can happen. Factors that will be analyzed in this ESVA method related to activity and socialization activities that occur in it. User activity in the building related to its users behavior patterns. Finally, the ESVA development through deepening the analysis of user socialization behavior patterns of the building will increase the accuracy of victim risk prediction disaster in buildings.
\end{abstract}

Keywords—Environmental, Facilities, Behavior, Pattern, Evacuation.

\section{INTRODUCTION}

C urrently, the safety of humans in their environment including in the building, becomes a very important research. This is because the human safety factor in the environment and the building is closely related to the number of earthquakes and natural disasters that occurred lately. In rescue disasters in the environment and buildings, research can be focused on two important activities. Two important activities are planning the evacuation route and planning the circulation of the circulation.

Good planning on two important points above, namely evacuation and circulation paths can be used as an effort to reduce (decrease) the number of disaster victims. But these two things are also very dependent on several other important factors. Important factors that influence it are; Number of users or visitors, supporting facilities and duration of activities.

For the activity factors that take place in the environment or also the building, becomes a separate study which is important because of the unique behavior and the many kinds of activities that are likely to occur. Furthermore, the variety of activities that many are designed by designer as an effort to enrich the user experience in the environment or building. Efforts to enrich the experience are aimed for the user to get satisfaction while in their environment. The states that spatial analysis of the movement of building users can be explored based on the pattern of socialization that occurred among users [1].

\section{METHOD}

A. Research method
This research will be executed by using qualitative method supported by some data from quantitative data. Qualitative method that used here is descriptive type. In this research, quantitative data were extracted from questionnaires to respondents. Quantitative data were extracted from the respondents obtained the direction of how the content and activities that occur in multifunctional buildings. This data needs to be explored because of the complexity of activities that can occur in the multi-purpose building. After getting an idea of how the best activity takes place based on the questionnaire, then there are further possible interpretations of the occurrence of human flows in the evacuation of disasters if they occur. In this interpretive activity, it is usually better known as predicting evacuation or disaster mitigation.

\section{B. Important factors are analyzed}

The arrangements of furniture, as well as the existing facilities in the building are then analyzed according to the schematic plan. This is to obtain a picture of the potential flow of human flows during evacuation and the critical points of human gathering. This analysis occurs because during a disaster, human accumulation will occur in the circulation of the evacuation route and the container of the human number (area) in the environment or the building. The statement of the building capacity is in line with the opinion of Sophie Nortona, Andrew Milatb, c, Barry Edwardsb, Michael Giffin (2016) which states that building capacity can be evaluated from program and organizational development [2].

\section{Steps of analysis}

As a final step, it will be carried out descriptive analysis of how the pattern of facility placement and 
August $1^{\text {st }}-2^{\text {nd }}$ 2017, Surabaya - Indonesia

flow of circulation. In order to get the maximum picture of a very good multi-function building, then we selected the building or showroom works. This building will be comparable to a museum or building with other showpiece functions. The exhibition space becomes very interesting chosen because of its ability in attracting the masses into the building because the users who come are among the existing ones with an adequate number. Another interesting factor of this showroom is the ability to modify activities as needed in the building. Those two things are the basic that makes the showroom building become the object of study in this research. The selected exhibition building here is a showcase of outstanding works at the Sepuluh Nopember Institute of Technology Surabaya in Research Centre Building.

\section{RESULTSAND DISCUSSION}

1. The initial condition of existing buildings and their potential for evacuation when a disaster occurs

The building used for the exhibition room of the Institute of Technology Sepuluh Nopember Surabaya is the Research Center of ITS. This building has one entrance from the bottom of the basement floor of this building. The Research Center Building ITS (RC) has one elevator as entrance to each floor as well as one door (ladder) safety on the west side of the building. This situation makes access to enter the building is concentrated from the bottom of the building. Especially for the 1st floor above the entrance basement is also located on the South side of the main entrance. Existing research center building is as shown in Figure 1 below.

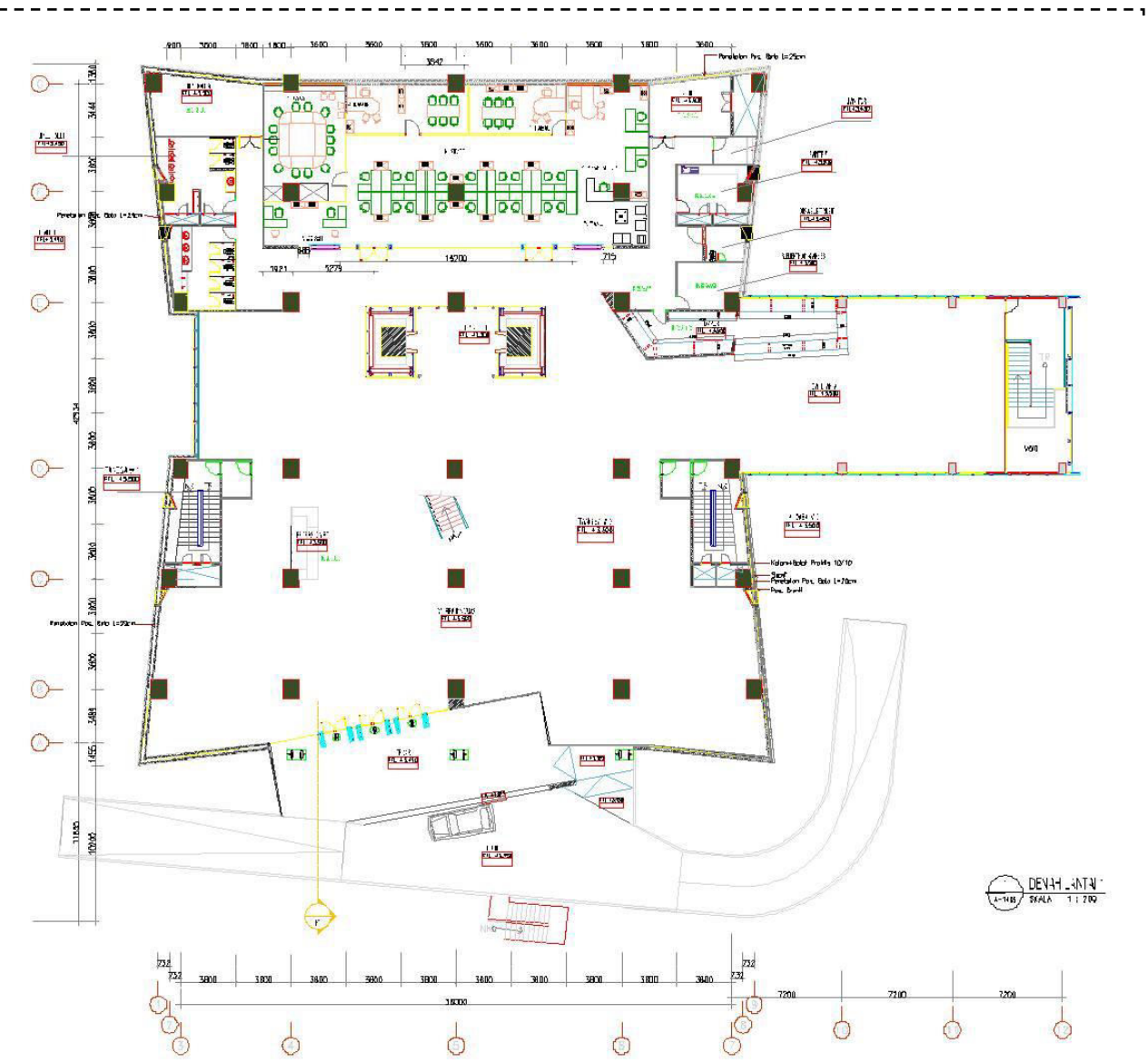

Figure 1. ITS Research Centre Building existing. 
August $1^{\text {st }}-2^{\text {nd }}$ 2017, Surabaya - Indonesia

Space to show off the masterpiece of ITS is on the 1st floor above the basement. This space is adjacent to the office of ITS Research Office (LPPM ITS). This space runs on the East and South sides of the building. This showroom has been equipped with a place for banquets and several lighting facilities for exhibition of his work. The above statement is in accordance with the opinion of Steven, Morton, Harvey, and Tijs, 2015 which states that segregation on the journey of daily activities can be analyzed by the usage daily pattern [3]. This analysis is conducted on social interaction in joint accessibility.

The entrance at the center of the elevator or from the South side can lead to the breaking of the first groove in circulation inside the showroom. Another situation is the side to put the exhibited works spread evenly but separated by the circular route to the elevator from the South and also the East. The existence of the above causes the unavoidability of areas of exhibition in the form of small islands. It can be seen at figure 2 below.
The showroom is geared to have complete facilities that will make the activities diverse in the building. That direction is a form of effort from satisfying the showroom visitors. The diversity of activities will offer more experience than those that do not offer.

The many experience of the many activities that can be carried out in the building is also an effort to hold longer visitors to stay and enjoy the existing showrooms. This effort had shown the success of an interior design. An interior design work is said to be a successful work if users want to longer stay in the building. This shows he really wants to be long stay on an interior design work. The results of questionnaires about visitors' wishes about the various activities that can be seen in the figure 3 below.

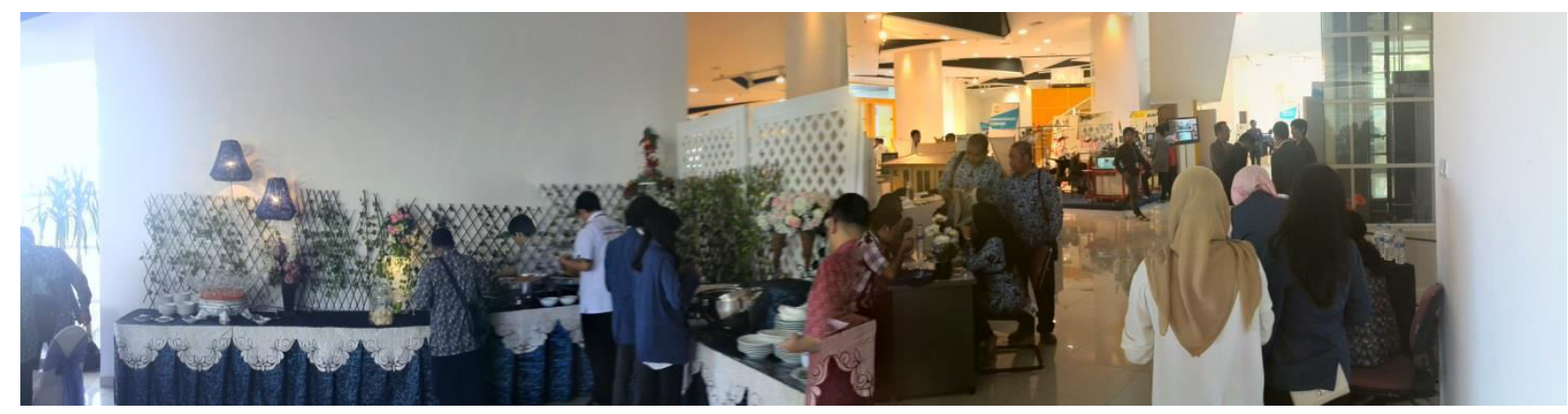

Figure 2.Area of the islands to showerase the works in ITS

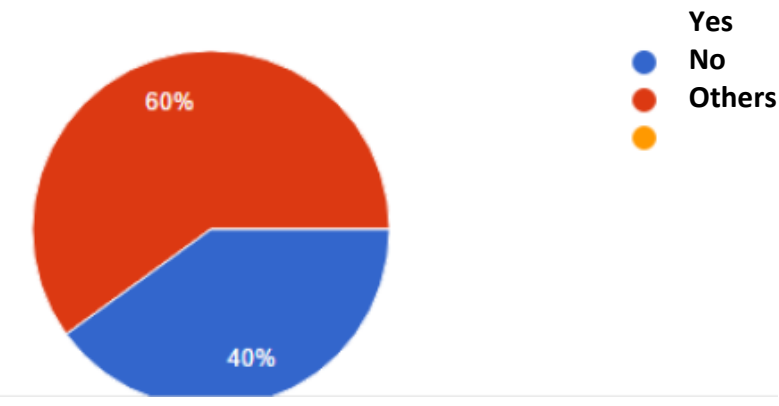

About Gallery and Hall of Fame at Lobby

Data Source: Putri Nova A.
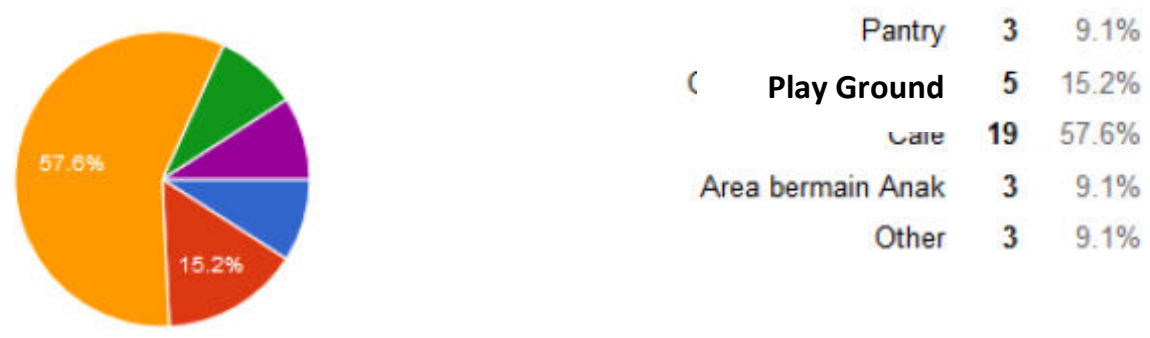

Idea ideas that can be included in the showroom Data source: Abel Rosanta

From the questionnaire data shows when the desired activity in the exhibit room or multifunctional space is

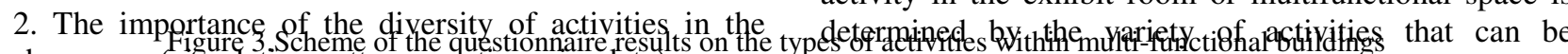
showroom (circulation pattern questionnaire data) implemented in it. The more various activities that can be implemented, the more successful the design is. 
3. Pattern of facility possibility placement in optimum show room

The prediction of the possibility of various facilities placement that will display is based on grouping the types of works on display. Based on this type of building function, the type of work on display is come from each faculty and study center in ITS. Due to the limitation of the exhibition space, the material that will display also be chosen which if very important only. As for other types of works that are very much in number, can still be exhibited in this space. But this can only be realized by way of visualization through the teleconferencing area in laboratories throughout the ITS.

The teleconferencing area of the showroom is highly dependent on the proximity to the other room when it receives the first visitor arrivals. Thus the location of the teleconferencing area is located in the center of the showroom. If all the existing facilities are arranged in this space it will become very crowded circulation area in the center of this showroom. Thus it is necessary to spread some activities in other areas. compiled based on the periodization of the development of a certain time. However, the composition of the exhibited material will be based on the interest of the event in a visit at the showroom. So another important factor to note here is the flexibility in the central area (center) to be organized according to the needs and objectives of a visit. The combined circulation shown at figure 4.

With the typical needs as above, then the showroom has a characteristic in the layout arrangement which always remain on the outer side of the room and a flexible in the middle of the showroom. In this show room the optimal circulation is centered on the middle of the room. It shown at figure 5 .

4. Disaster mitigation planning through the importance of capacity calculation and the pattern of human movement in multi-functional buildings

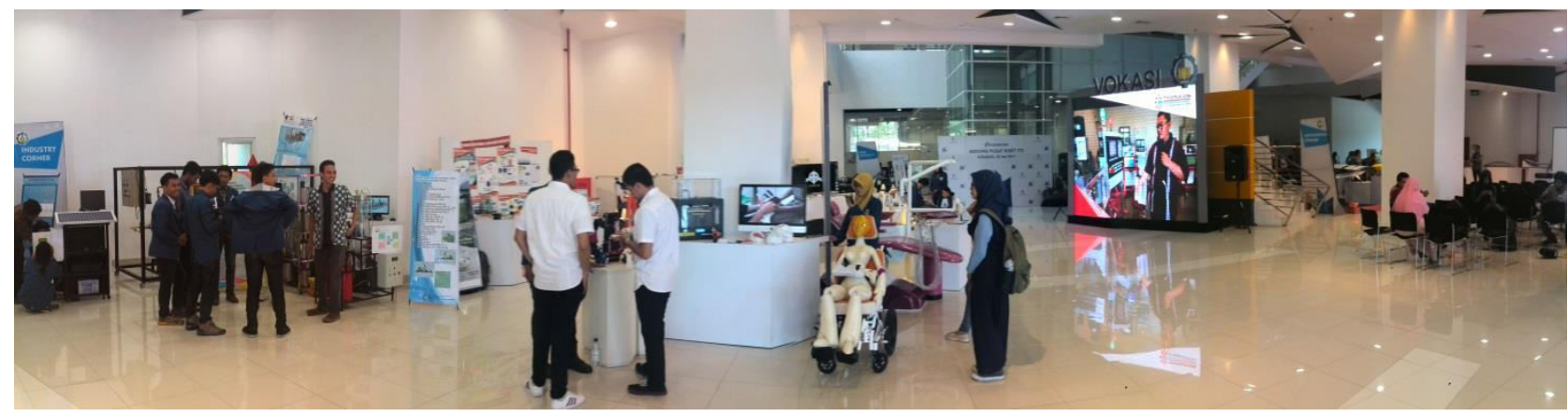

Figure 4.The combined circulation patterns spread and centered on the center of the showroom

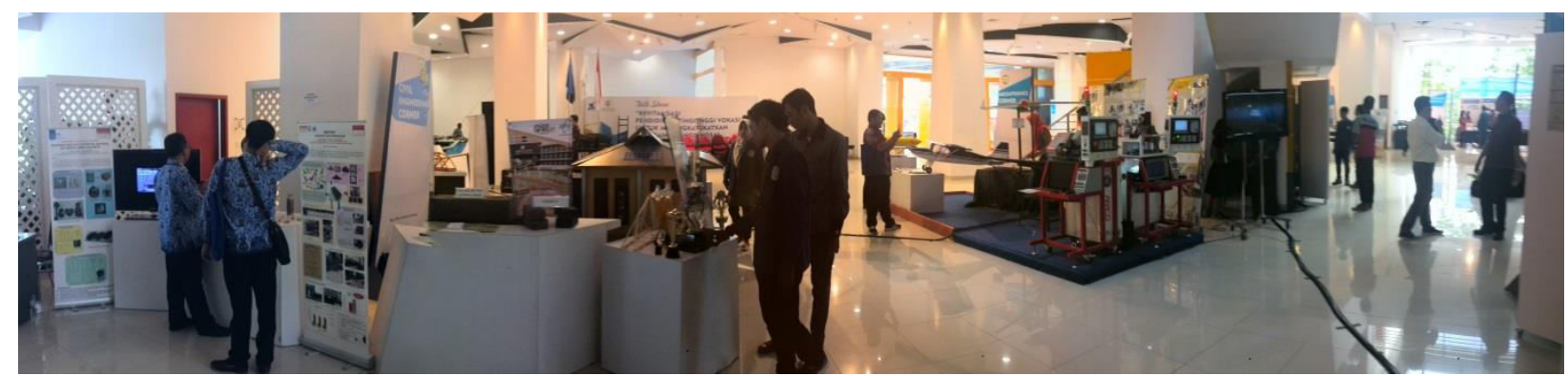

Figure 5.The calculation of the density of visitors at the showroom and the circulation path

4. Circulation pattern and movement of activity in showroom building as multi-function building Circulation in showrooms usually always have a certain flow. This is because the design of the circulation is based on the desire to see the work in a certain order. At the museum for example, the flow of circulation will be arranged based on a certain period of time. While in the exhibition space studied, this does not need to be
Disaster mitigation in the showroom can be realized with the clarity of the evacuation flow and the spread of the number of visitors on all sides of the showroom. Clarity in the flow of circulation is manifested through adequate sign and circular dimensions. While on the spread of visitors can be optimized through the planning of the distribution of works on display. Both of these will facilitate the evacuation of the large number of visitors in 
August $1^{\text {st }}-2^{\text {nd }}$ 2017, Surabaya - Indonesia

a short time. Planning of circulation is determined from the estimation of the number of people who are along the circulation path. The above analysis is in line with the opinions of V. Wagnera, KW Kallusa, NJ Neuhubera, M. Schwarzb, H. Schrom-Feiertagc, S. Ladstaetterb, L. Palettab (2015) which states that the evacuation design on the environment is an important concern of human Factor. Human behavioral aspects (including users of the environment and buildings) in specific situations can be explained by explanation and analysis of barriers to behavior [4].

Furthermore, the number of people should be able to flow smoothly to the exit on the nearest side. Factors that need to be observed here include the utilization of the circulation path as a place for people to stop to see the work on display.

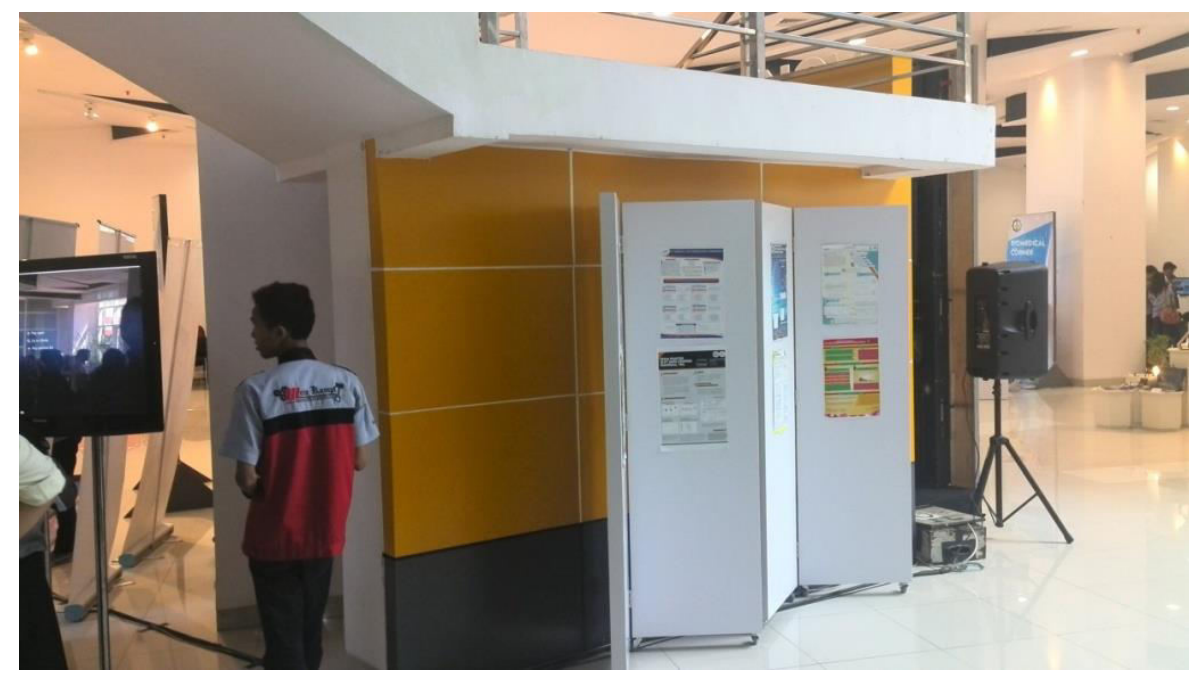

Figure 6.The central part of the RC building which became the center of circulation

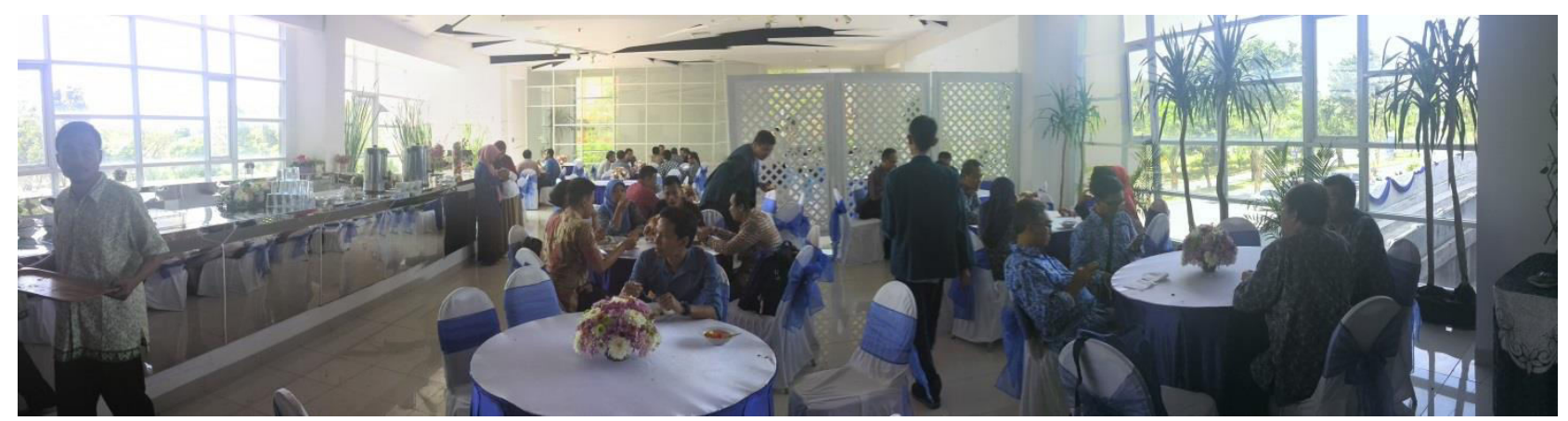

Figure 7.The banquet center became an important part of the showroom at the RC building

On the distribution of the number of visitors is also determined by the maximum distribution of the number of people who are in a work area on display. This distribution is in accordance with the islands to showcase existing works. Based on the capacity of each island where the exhibition of works it will be able to know the description of the space capacity distribution. The center of $\mathrm{RC}$ and the banquet venue can be seen in the figure 6 and 7 below.

\section{REFERENCES}

[1] M. Wardhana, "Spatial analysis of users movement pattern and its socialization on public facilities and environment through the ESVA," in Procedia - Social and Behavioral Sciences, 2016.

[2] S. Nortona, A. Milatb, B. Edwardsb, and M. Giffin, "Narrative review of strategies by organizations for building evaluation capacity," Eval. Program Plann., 2016. 
The Third International Conference on Civil Engineering Research (ICCER)

August $1^{\text {st }}-2^{\text {nd }}$ 2017, Surabaya - Indonesia

[3] S. Farber, M. O’Kelly, H. J. Miller, and T. Neutens, "Measuring segregation using patterns of daily travel behavior: A social interaction based model of exposure," J. Transp. Geogr., pp. $26-38,2015$.

[4] V. Wagnera, K. W. Kallusa, N. J. Neuhubera, M. Schwarzb, H. Schrom-Feiertagc, and L. P. S.
Ladstaetterb, "Implications for behavioral inhibition and activation in evacuation scenarios: Applied human factors analysis," in Procedia Manufacturing, 2015. 